\title{
COMMNICOIIIONS
}

Ronald Bastovansky - Michal Tropp - Michal Lukac - Frantisek Brumercik*

\section{MOLYBDENUM SHEET METAL TEST DEVICE}

The paper presents the construction of a device that allows processing the Baosteel/Sanchez experiment. The experiment simulates the brake ribs by deep drawing of the molybdenum sheet metal.

Keywords: Baosteel/Sanchez experiment, brake ribs, molybdenum sheet metal.

\section{Introduction}

The improvement of the optical and laser single crystals production technology from the melt of leucosapphire and yttriaallumina garnet (YAG) largely determines the success of the most important directions in the development of microelectronics, energy, optoelectronic and laser technology. The range of positive properties of sapphire monocrystalline is very wide - generation, amplification and transmission of electromagnetic waves. Such widespread use of single crystal sapphires is possible due to their unique properties - high optical uniformity and clarity in a wide range of light wavelengths, radiation resistance and also high mechanical, thermal and dielectric properties [1 - 2].

Large demand for bulk of sapphire optical products, which are widely used as illuminators, optical windows in aviation and aeronautics etc., generates the inquiry of effective production of high quality industrial crystals.

\section{Horizontal crystallization method}

Especially for these products the horizontal single crystal sapphire crystallization method is suitable - the so called Bagdasarov method (Fig. 1).

Without encompassment of the production technology of this special container made from thin molybdenum sheet it is not realistic to consider the productive exploitation of horizontal crystallization systems in engineering practice. The optimal shape and geometry will provide safe growth of sapphire single crystal (Fig. 2).

\footnotetext{
* Ronald Bastovansky, Michal Tropp, Michal Lukac, Frantisek Brumercik Mechanical Engineering Faculty, University of Zilina, Slovakia

E-mail: brumercikf@fstroj.uniza.sk
}

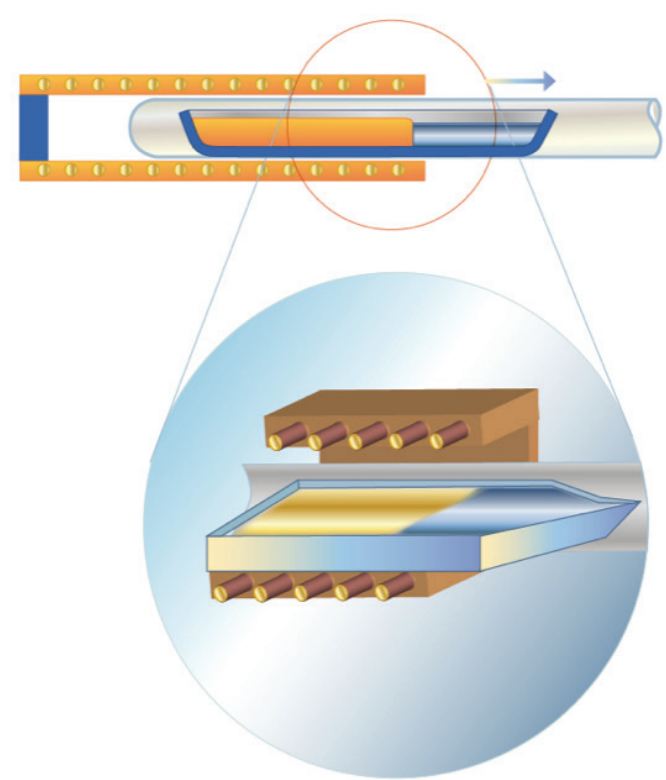

Fig. 1 Horizontal single crystal sapphire crystallization (Bagdasarov) method (Source: [3])

The technology of crystal growth is based on putting the crystal seed into the front of the crucible. The crucible is slowly moving in the vacuum passing the heating area, then the melting area and finishing in the cooling (crystallization) area. This method allows to create relatively large single crystals with relatively high velocity of grow $(8-10 \mathrm{~mm}$ per hour) with precise shapes in more crystallographic directions [4].

The success of the described method depends on the shape of the molybdenum crucible, its adhesion to single crystal surface and its fast and repeatable production. 

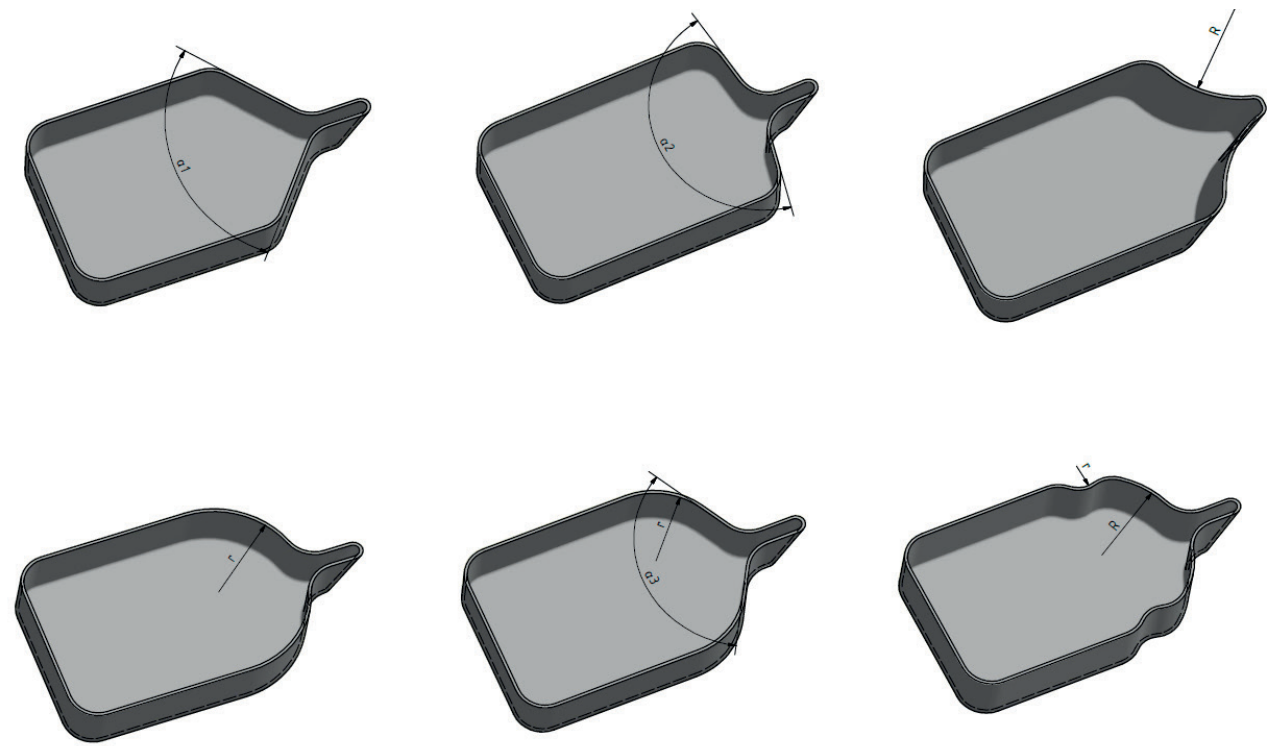

Fig. 2 Possible shapes of crystallization container (Source: authors)

\section{Molybdenum sheet properties}

The production of the molybdenum sheet is difficult. The quality of the molybdenum sheets varies in a wide range - they are very fragile and cold-short. It is demonstrated almost in every first draw, where the micro cracks are observable. The second draw increases the cracks created in the first draw. Thus, it is very difficult to draw the drawn part up to the height equal to the diameter of the part $(55 \%$ of the overall reduction of the blank area).

The cracks appear always if the deformed sheet is wrinkled after the first draw. When the second draw is applied, the waves are getting straight and the sheet bent in the opposite direction cracks. According to this fact, the sheet blank has to be held all the time of the drawing process [5 - 6].

The draw beads and lock beads mean that the material flow can be controlled, fine-tuned by FEM simulation and ultimately the toolmaker's experience, so that the defects of cracking, overreduction of sheet thickness and wrinkling can be avoided.

Instead of the blank holder and the draw and lock beads, the forming die radius is also very important. If the radius is too small, the sheet gets cracked. If the radius is too large, the blank gets wrinkled at the edge [7]. The choice of the radius value influences not just the bead dimension, but also the drawing material.

\section{Baosteel/Sanchez experiment principle}

To obtain the right blank holder force and the die edge curvature, the Baosteel/Sanchez experiment was done. The test device developed for this experiment allows changing the die edge radii and simulating various blank holder forces, which causes the change of the draw beads versus blank friction coefficient [8].

Figure 3 shows the principle of the experiment. The sheet metal strip with the thickness $c$ is drawn through the bunch of rotating guiding cylinders (rotation friction is omitted) with the drawing force (DBRF) and the couple of nonrotating bending cylinders and one holder cylinder held down to the moving strip with the holding force (HDF). The radii of the holder and bending cylinders $R, r_{1}, r_{2}$ are variable. The value of the holding force HDF depends on the depth of the holder cylinder push $H$ [9].

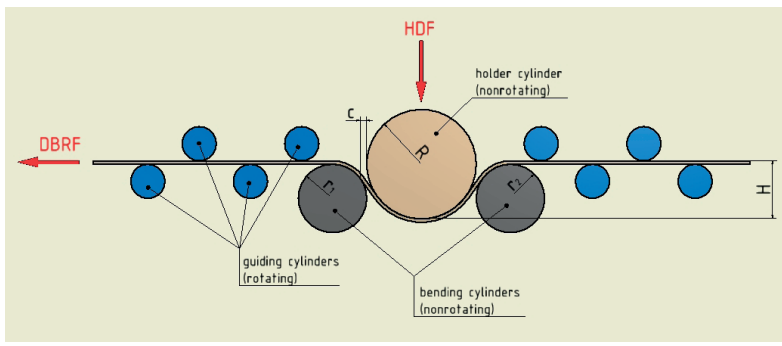

Fig. 3 Baosteel/Sanchez experiment principle (Source: authors)

\section{Test device structure}

The experimental device was designed according to the principle of the Baosteel/Sanchez experiment [10]. The 3D model of the developed device is shown in Fig. 4. It can be mounted to the test machine LabTest 5.20ST (Fig. 5). The test device allows to:

- test molybdenum strips of 0.5 - $1 \mathrm{~mm}$ thickness; 
- record the value of the DBRF force to $30 \mathrm{kN}$ by the test machine sensor;

- record the value of the HDF force to $10 \mathrm{kN}$ by the built-in force sensor;

- variable adjust the depth of the holder cylinder H;

- change the radii of the bending and holder cylinder $\mathrm{R}, \mathrm{r}_{1}, \mathrm{r}_{2}$ by the simple replacement of the cylinders with another radii or other shaped bending / holder parts;

- change of the friction coefficient between the bending and holder cylinder and the molybdenum sheet by the selection of the cylinder material and surface;

- heating of the molybdenum blank up to $400^{\circ} \mathrm{C}$;

- shielding option supplied by the inert gas ambience (Ar).

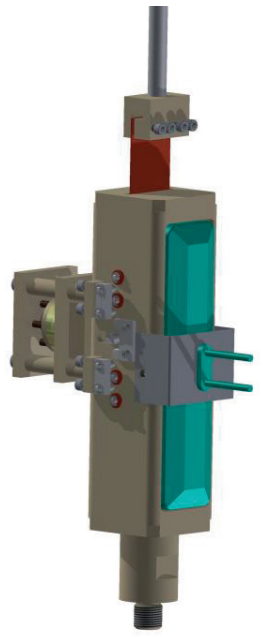

Fig. 4 3D model of the developed Baosteel/Sanchez test device (Source: authors)

\section{Measurement conditions}

The experiment specimen will be the molybdenum strip made from the molybdenum nano-powder rolled and sintered by particular layers [11 - 12].

The molybdenum sheet sample with maximum dimensions of $50 \times 300 \mathrm{~mm}$ has to be put between the guiding valves and clamped to the test device jaws. The clearance between the guiding valves and the blank is then terminated and the holder cylinder is moved towards the blank. The holder cylinder movement causes in the blank the press offset - the desired depth $H$. The DBRF force is recorded by the measuring system connected to the laptop and the HDF force will be followed on the oscilloscope. The heating will be provided by the ceramic heater FFE - 1000W. The body of the test device is manufactured from the heat-resistant material AISI $309 / 310$ that resists up to $400^{\circ} \mathrm{C}$. The test device is insulated by the insulating coat to prevent the heat leakage. The sensors are equipped with coolers to prevent their damage by high test temperatures [13 - 16].
To prevent the oxidation of the molybdenum sheet, inert gas (Argon) can be put into the test device. The gas is put to the test device chamber by small overpressure, which causes the air crowding-out [17].

The temperature will be measured on the top and bottom part of the molybdenum sheet by a pair of thermocouples [18].

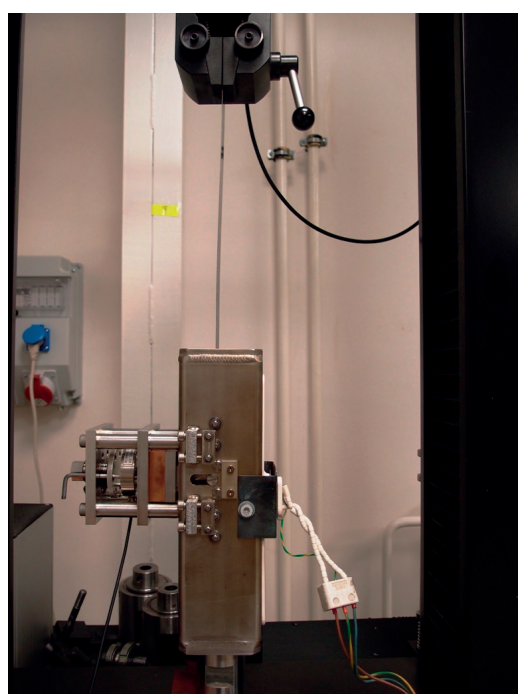

Fig. 5 Test device mounted in the test machine

(Source: authors)

\section{Conclusion}

The test procedures on the presented test device can be done up to the temperature of $400^{\circ} \mathrm{C}$. The research procedures available using the presented test device can be described as follows:

- research of the press offset depth and holding force dependence,

- the influence of the temperature increase and the inert gas atmosphere to the deformation process,

the friction coefficient change between the molybdenum sheet and the holder cylinder by the holder cylinder lubrication,

- verification of the suitability of the holder cylinder material and hardness.

\section{Acknowledgement}

This paper presents results of work supported by the Slovak Scientific Grant Agency of the Slovak Republic under the project No. VEGA 1/0077/15. 


\section{References}

[1] MARTIKAN, M., BRUMERCIK, F, BASTOVANSKY, R.: Development of Mechatronic Deformation System. Applied Mechanics and Materials, 803, 2015, 173-178.

[2] BRUMERCIK, F., BRUMERCIKOVA, E., BUKOVA, B.: Mechatronic and Transport System Simulation. Applied Mechanics and Materials, 803, 2015, 201-206.

[3] http://www.miracrys.com/CCinit.php?id=technologyam_4

[4] GLOWACZ, A.: Diagnostics of DC and Induction Motors Based on the Analysis of Acoustic Signals. Measurement Science Review, $14,5,2014,257-262$.

[5] ZMINDAK, M., DONIC, T., JURIK, P.: Numerical Simulation of Rectangular Deep Draw Containers Made from Thin Molybdenum Sheet. IOP conference series: Materials Science and Engineering, 159, 2016, 8.

[6] KOHAR, R., HRCEK, S.: Dynamic Analysis of a Rolling Bearing Cage with Respect to the Elastic Properties of the Cage for the Axial and Radial Load Cases. Communications - Scientific Letters of the University of Zilina, 16, 3A, 2014, 74-81.

[7] HRCEK, S., KOHAR, R., MEDVECKY, S.: Determination on the Maximum Roller Bearing Load with Regards to Durability thereof Using FEM Analysis. Communications - Scientific Letters of the University of Zilina, 14, 3, 2012, 55-61.

[8] DROZDZIEL, P., KOMSTA, H., KRZYWONOS, L.: Repair Costs and the Intensity of Vehicle Use. Transport Problems, 8, 3, 2013, 131-138.

[9] MACHALEK, J.: Projects of Progressive Production Technologies of Parts from Sheet-Metal with the Use of Finite Elements Method. Dissertation thesis, Ostrava, 2012.

[10] KOHAR, R., HRCEK, S., MEDVECKY, S.: Usage of Dynamic Analysis to Determine Force Interactions between Components of Rolling Bearings. Communications - Scientific Letters of the University of Zilina, 14, 3, 2012, $62-67$.

[11] KOMSTA, H., BRUMERCIKOVA, E., BUKOVA, B.: Applications of NFC Technology in Passenger Rail Transport. Transport Problems, 11, 3, 2016, 43-53.

[12] DROZDZIEL, P., KRZYWONOS, L.: The Estimation of the Reliability of the First Daily Diesel Engine Start-Up during its Operation in the Vehicle. Maintenance and Reliability, 1, 41, 2009, 4-10.

[13] BRUMERCIKOVA, E., BUKOVA, B., KRZYWONOS, L.: NFC Technology in Public Transport. Communications - Scientific Letters of the University of Zilina, 18, 2, 2016, 20-25.

[14] FATURIK, L., TRSKO, L., HRCEK, S., BOKUVKA, O.: Comparison of Structural Design in High and Ultra-High Cycle Fatigue Regions. Transactions of FAMENA, 38, 4, 2014, 1-12.

[15] CABAN, J., DROZDZIEL, P, VRABEL, J., SARKAN, B., MARCZUK, A., KRZYWONOS, L., RYBICKA, I.: The Research on Ageing of Glycol-Based Brake Fluids of Vehicles in Operation. Advances in Science and Technology, 10, 32, 2016, 9-16.

[16] CABAN, J., MARCZUK, A., SARKAN, B., VRABEL, J.: Studies on Operational Wear of Glycol-based Brake Fluid. Przemysl Chemiczny, 94, 10, 2015, 1802-1806.

[17] MALIK, L., HRCEK, S.: General Calculation Model of the Gear Mechanisms with Step and Continuously Gear Ratio Change (in Slovak), University of Zilina, 2016. ISBN 978-80-554-1239-9.

[18] CACO, M., TRIBULA, R., SCERBA, P., DZUBRIAK, J., KOHAR, R.: Automatic E-frame - Increase of the AGV System Utility Value (in Slovak), ProIN, 17, 1, 2016, 34-37. 